\title{
Lichen sclerosus: the role of oxidative stress in the pathogenesis of the disease and its possible transformation into carcinoma
}

This article was published in the following Dove Press journal: Research and Reports in Urology

\author{
Gianni Paulis ${ }^{1,2}$ \\ Enzo Berardesca ${ }^{3}$ \\ 'Andrology Center, Villa Benedetta \\ Clinic, Rome, Italy; ${ }^{2}$ Department of \\ Uro-andrology, Castelfidardo Medical \\ Team, Rome, Italy; ${ }^{3}$ Department of \\ Clinical Dermatology, S. Gallicano \\ Dermatological Institute, Rome, Italy
}

Correspondence: Gianni Paulis Andrology Center, Villa Benedetta Clinic, CAP 00185, Rome, Italy

Tel +3906 428I 42II

Fax +3906 4885081

Email info@labcastelfidardo.it

\begin{abstract}
Lichen sclerosus (LS) is an autoimmune chronic inflammatory disease usually involving the anogenital skin of both sexes; more rarely LS exclusively involves extragenital areas. As a chronic inflammatory disease, in most cases, LS evolves and progresses causing scleroatrophy of the skin or scars which may cause stenosis in the affected areas. A few LS patients are at risk of developing squamous cell carcinoma in their lifetime, but appropriate long-term treatment diminishes the possibility of a malignant evolution. Oxidative stress (OS) has been proven to play a role not only in the pathogenesis of LS, but also in the development and progression of the disease. OS, by causing DNA damage and lipid peroxidation, contributes directly to the possible malignant transformation of LS. Moreover, the increase in oxidative DNA damage is associated with mutations in tumor suppressor genes. Considering the role that OS plays in LS, therapeutic use of antioxidants appears to be rational and possible, in association with other treatments. Antioxidants would counteract the oxidative DNA damage, which is the most important factor for the progression of LS and its malignant transformation.
\end{abstract}

Keywords: lichen sclerosus, oxidative stress, reactive oxygen species, oxidative damage, antioxidant therapy, squamous cell carcinoma

\section{Introduction}

Lichen sclerosus (LS) is a chronic inflammatory disease involving the genital skin and mucous membrane of both males and females; the disease course is chronic, relapsing, and sometimes remitting. LS is an autoimmune disease, and LS patients have a higher risk of suffering from other autoimmune diseases.

The disease used to be called almost exclusively Lichen sclerosus et atrophicus but Lichen sclerosus is more appropriate, since LS patients may often present with areas of thickening and hyperplasia.

In most cases (83-98\% of cases) in both sexes LS affects the perianal and genital areas, more rarely it exclusively involves extragenital areas (neck, shoulders, trunk and back, buttocks, breasts, upper arms, axillae, umbilical region, wrists, nipples, face, around the ankles, palms and soles, etc.); even more rarely, extragenital LS may affect the mucous membrane of the lips, mouth, and palate. ${ }^{1-3}$ Symptoms mostly include pruritus and pain at affected sites. In about $15-20 \%$ of cases, extragenital lesions may accompany anal-genital LS. ${ }^{4}$ LS affects people of all ages, and is more common in women than in men, with a ratio that varies between $6: 1$ and 10:1. ${ }^{5}$ While in males genital LS mainly affects the glans penis and the prepuce (Balanitis xerotica 
obliterans-BXO), in females, it affects vulvar, perineal, and perianal skin. Even though certain age ranges are more exposed to the disease, LS can occur at any age. In females, LS incidence peaks at the periods in life with lower estrogen production (prepubertal and postmenopausal ages); even in males, the disease may affect both children and adults. ${ }^{1,3,6}$ It is difficult to determine the exact prevalence of LS for various reasons: very often, patients do not see a doctor, either because they have no symptoms or because they are ashamed or embarrassed, or LS is not diagnosed because patients present to specialists who are often not adequate for the type of disease. ${ }^{7}$ In any case, even though it is certainly an underestimation, the literature reports an LS prevalence of $3 \%$ in adult women and $0.07 \%$ in males (BXO). ${ }^{6,8,9}$

In adult women, genital LS very often causes vulvar pruritus (often even at night) accompanied by pain when skin erosion and fissuring are present; in this case, dyspareunia may also occur, especially if a narrowing of the vaginal introitus is already present due to labial fusion; fusion of the clitoris hood with the clitoris may even occur, and as a consequence, keratin debris may accumulate, forming something like a pseudocyst, which may cause pain. ${ }^{6}$ Urinary symptoms are only present only when the nearby urethral meatus is involved, and pain during bowel movements is also possible when LS also affects the perineum and perianal region. 4,6

LS symptoms in males ( $\mathrm{BXO}$ ) can be absent, as often occurs in children, in whom, however, phimosis is often present. ${ }^{10,11}$ Symptoms in males correlate with disease progression: itching, penile pain both at rest and during erection, and dysuria in case of urethral stenosis. ${ }^{4}$

Extragenital LS is normally asymptomatic; skin lesions may, however, cause local dryness and itching.

There is no general consensus about the etiology of this disease, although there is evidence that autoimmune mechanisms are involved in its pathogenesis. ${ }^{6,12-16}$ LS is very often associated with other autoimmune disorders, such as thyroid diseases, alopecia areata, vitiligo, diabetes mellitus, pernicious anemia, and cicatricial pemphigoid. ${ }^{4}$

In females, it is most frequently associated with an autoimmune thyroid disorder (Hashimoto's thyroiditis, etc.) with a percentage that varies in the literature between $16.3 \%$ and $39 \%$, whereas in males this occurs less frequently, with percentages varying in the literature between $5.1 \%$ and $15 \%$. In males, LS is more commonly associated with vitiligo, autoimmune thyroid disease, diabetes mellitus, alopecia areata, ulcerative colitis; incidence, however, varies depending on the study and likely between geographical areas, as well. ${ }^{14,17-19}$
Furthermore, a significant association has been found between LS and HLA class 2 antigen DQ7. ${ }^{20-22}$ Genetic predisposition is very likely to present, and possibility of family recurrence has been demonstrated several times. $^{23,24}$

However, although several studies detected a genetic predisposition to LS, this has not been proved in all patients affected by the disease. ${ }^{24}$ Although several studies showed that relatives of LS patients have a higher risk of developing LS, usually only a low percentage of LS patients (12\%) present a family history of the disease; consequently, one must deduce that although there is a genetic component in the etiology of LS, the component is not decisive for the development of the disease in all patients. ${ }^{24}$

Chronic exposure to urine has been postulated as possible causal factor of genital LS, since the presence of urostomy has often been recorded as being associated with peristomal LS. ${ }^{7,25}$ Even exposure of the skin to trauma (Koebner's phenomenon) has been proposed as possible LS trigger. $4,6,7,26$

The hypothesis that onset of LS may be triggered by Borrelia or Epstein-Barr virus infection has been the object of various studies, but results have been discordant. ${ }^{4,7,27,28}$

The fact that LS is more common in the peri- and postmenopausal ages suggests that hormones play a role in the pathogenesis of the disease. ${ }^{5,29}$

LS has considerable impact on quality of life, frequently causing psychological effects, including insomnia (19\%), anxiety (58\%), and depression $(27 \%))^{30-32}$ The disease also inevitably has an impact on the sex life of both women and men, due to the morphological changes and pain in the affected areas. ${ }^{4,32}$ As a chronic inflammatory disease, in most cases, LS evolves with progression of local lesions, both in females and males, but spontaneous remissions have been described both in girls $(25 \%$ of cases) and in male subjects ( $27 \%$ of cases). ${ }^{7,17,29}$

\section{Clinical features of LS}

In adult women, lesions present more often as light-colored papules or whitish or ivory patches often accompanied by erosions, fissuring, purpura, areas with ecchymoses, and occasionally hyperkeratosis. Since LS is a scarring dermatosis, in the most advanced stages, atrophy and sclerosis may cause loss of the labia minora, introital stenosis, and agglutination of the clitoral hood (vulvar kraurosis) (Figure 1); if the perineal and perianal areas are involved, the following might be present: rash, scleroatrophy of the skin, erosion, fissures, or scars, which in rare cases may cause anal stenosis. ${ }^{4,6,7,29}$ 


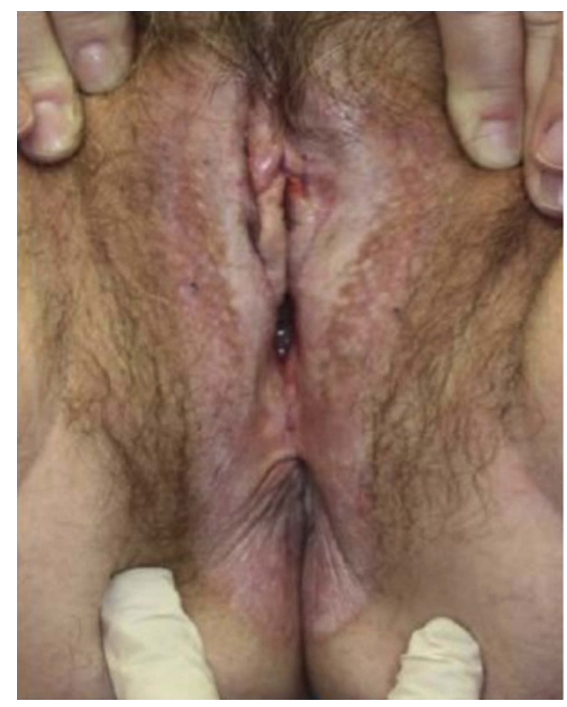

Figure I Whitening of the vulva extending to the perianal skin, fusion and resorption of labia minora and consequent vaginal and anal stenosis.

The appearance of LS lesions in girls is similar to that in adult women, but ecchymoses are more common (Figure 2), which can lead to believe that the lesions are caused by sexual abuse (which can in any case coexist); perianal involvement is also more frequent in girls. ${ }^{4,6,7}$

In male children, the disease simply presents with more or less full phimosis, though in some cases, as in adults, it can present as cutaneous hyperemia, which in time can transform into a depigmented area (Figure 3). ${ }^{10,11,29}$ In

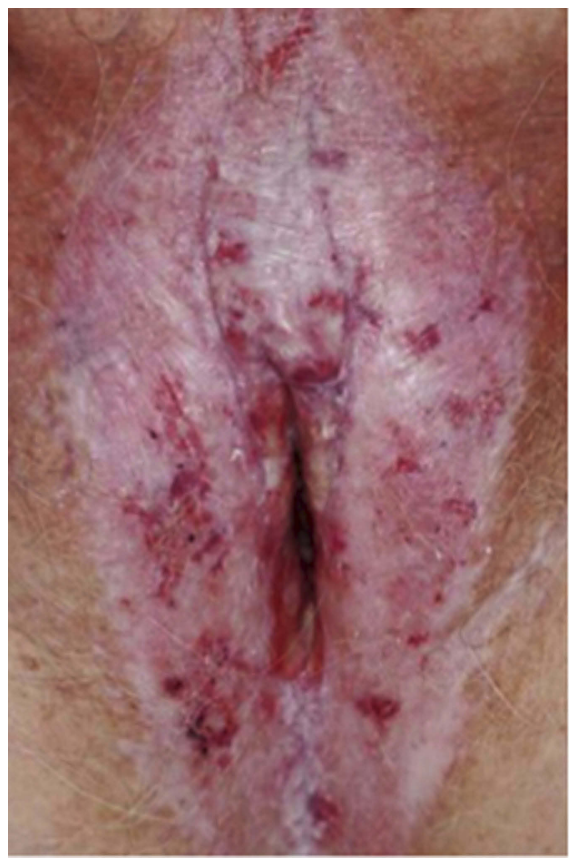

Figure 2 Thin, white and wrinkled skin localized to vulva and ecchymosis.

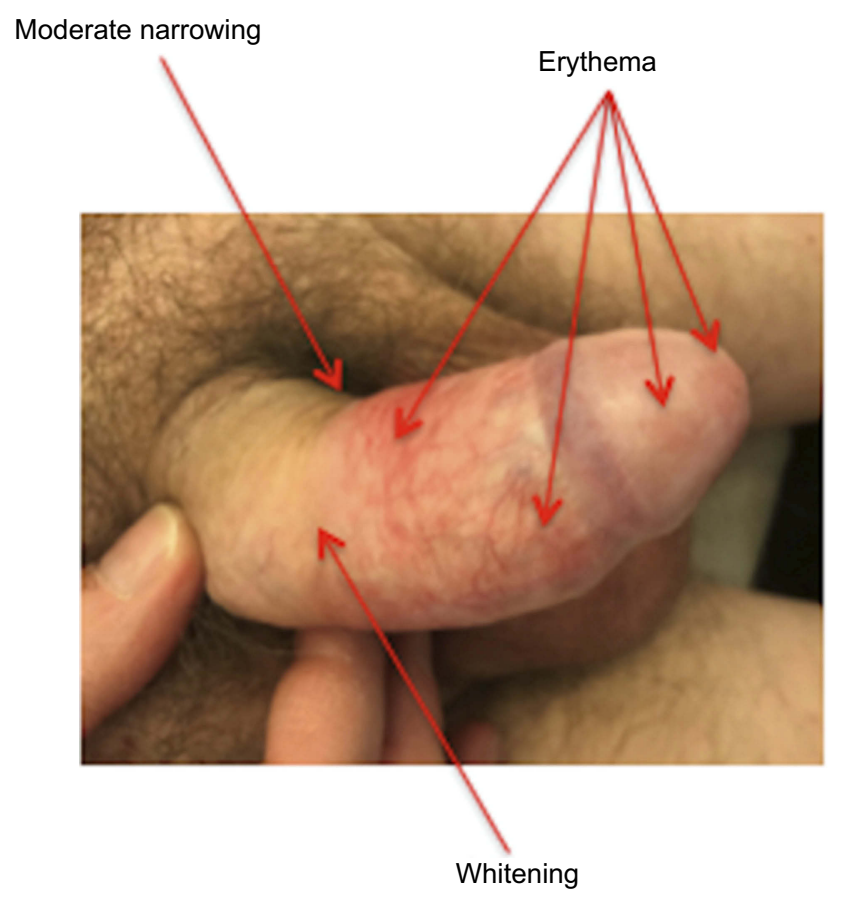

Figure 3 Early stage of BXO. Partial whitening and sclerosis of the preputial skin (moderate narrowing). Erythematous areas of the foreskin and the glans.

adult males, the following areas may be involved: skin of the prepuce, glans penis, coronal sulcus, frenular area, and urethral meatus.

As the disease progresses, it becomes difficult to uncover the glans, and in the most advanced cases, there may be ulceration, balanopreputial adhesion, difficulty in retracting the foreskin, even up to full phimosis, paraphimosis, and painful erections, skin fissuring in the tight and narrowed preputial ring, and stenosis of the urethral meatus and urethra. The urethral meatus is involved in $4 \%$ of cases (Figure 4). Urethral involvement is present in males in $20 \%$ of cases and can manifest as narrowing of the distal urethra, which, in case of further progression, can involve both the penile and the bulbar urethra. ${ }^{29,33}$

In extragenital LS, initial macroscopic appearance consists in whitish papules, which subsequently merge into more ample ivory-white plaques, at times accompanied by bruised areas and occasionally hyperkeratosis. ${ }^{6,7}$ Koebner's phenomenon is often present in cases of extragenital LS, and occurs in the areas that are more subject to pressure or chafing, and where there are old scars, urostomies, or skin areas that have undergone radiotherapy. ${ }^{6,7,26,29}$

\section{Histological features of LS}

Histologically, BXO has the same characteristics as LS, ie, atrophy of the epidermis, with flattening of the epithelial 


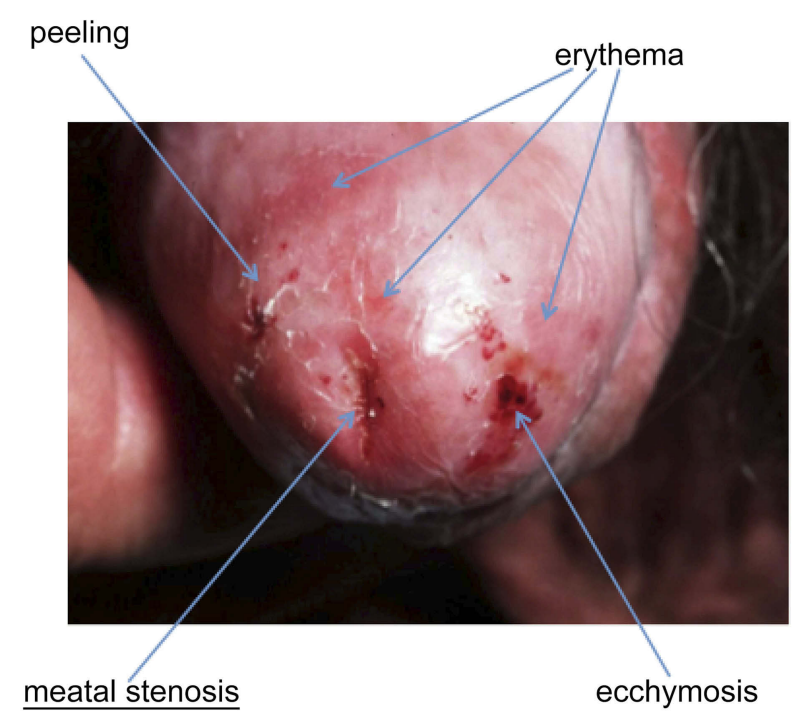

Figure 4 Urethral meatal stenosis associated with erythema, ecchymosis and peeling of the glans skin.

extensions that project into the underlying connective tissue (rete ridges), orthokeratotic hyperkeratosis (anuclear keratin layer), basal cell degeneration, vacuolar interface changes, dermal hyalinization with a bandlike lymphocytic infiltrate, along with loss of elastic fibers and vasculature. ${ }^{7,34,35}$

In the early stages of LS, histological features can overlap with those observed in psoriasis and lichen planus, ie, luminal hyperkeratosis and hypergranulosis of the adnexal structures, slight irregular acanthosis (which may be psoriasiform), and thickening of the basement membrane. ${ }^{7}$ Furthermore, in early LS subepithelial edema, homogenization of collagen (hyalinization), and dilated blood vessels right under the basement membrane are observed in the dermis. ${ }^{7}$ However, hyalinization of the superficial dermis can be absent in the early stages of the disease. $^{34}$

Epidermal atrophy is thus observed, the epidermis gradually thins and the dermis gradually thickens, due to the increased deposit of collagen fibers.

\section{Diagnostic procedures}

Normally, clinical presentation is sufficient for an experienced physician to diagnose LS. ${ }^{6,7,29}$ Biopsy is, on the other hand, strongly recommended before starting treatment and in the following cases (in any case, biopsy should not be performed earlier than 4 weeks after interruption of any previous local treatment):

when the appearance of the lesion is not clear, due to other possible diseases that mimic LS; when cancer is suspected; when no improvement has occurred after an adequate period of treatment. ${ }^{6,7,29}$

\section{LS and risk of malignancy}

The possibility of malignant transformation into squamous cell carcinoma (SCC) almost exclusively concerns genital LS (Figures 5 and 6); extragenital LS can evolve into SCC much more rarely: a single case has been reported in the literature. ${ }^{36}$ It is estimated that about $5-6 \%$ of LS patients are at risk of developing SCC in their lifetime, but appropriate long-term treatment diminishes the possibility of a malignant evolution of LS. ${ }^{4-7,29,37}$

A number of studies have contributed to confirm the risk of malignant evolution of LS, showing that about $60 \%$ of patients with vulvar SCC were already affected by genital LS. ${ }^{6,38-40}$ With regards to the risk of malignant transformation of genital LS in the male, Powell et al (2001) showed that $50 \%$ of patients suffering from penile SCC also had histological evidence of LS (Figure 6). ${ }^{41}$ Nasca et al (1999), in a study on 86 cases of male genital LS, observed a transformation into penile carcinoma in 5 cases (5.8\% of cases). ${ }^{42}$ Barbagli et al (2006), in a study on 130 males suffering from LS, observed that penile carcinoma developed in 11 cases $\left(8.4 \%\right.$ of cases). ${ }^{43}$ The time interval between the onset of LS and development of penile neoplasm is between 10 and 23 years. ${ }^{43}$

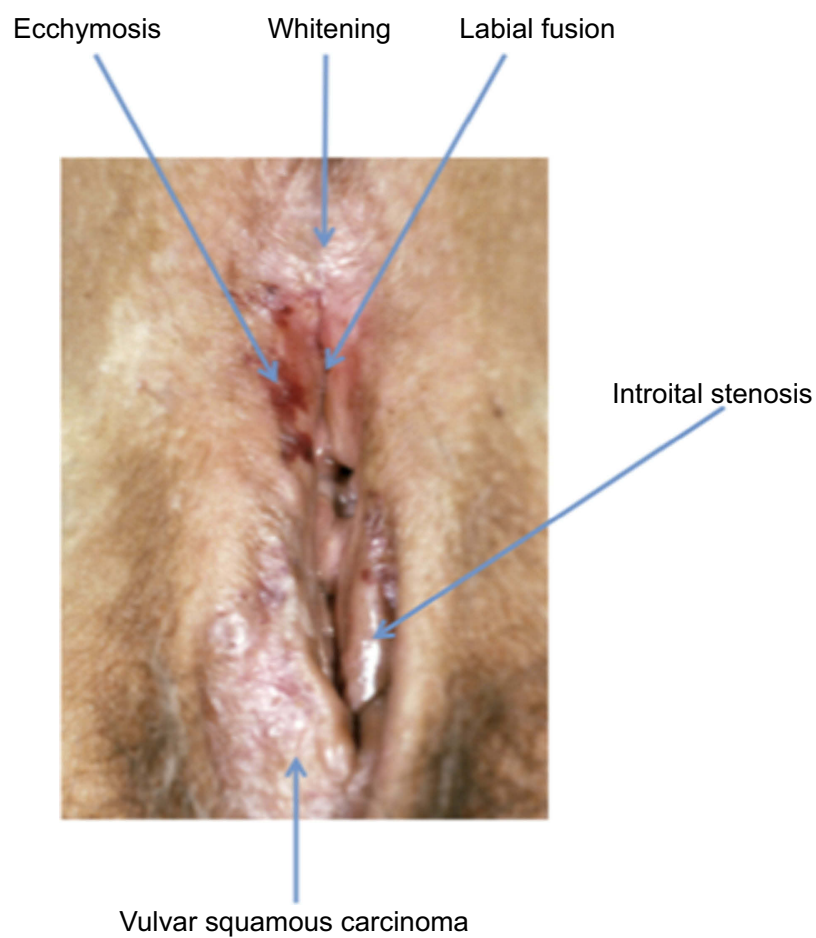

Figure 5 Lichen sclerosus associated with vulvar squamous cell carcinoma. 


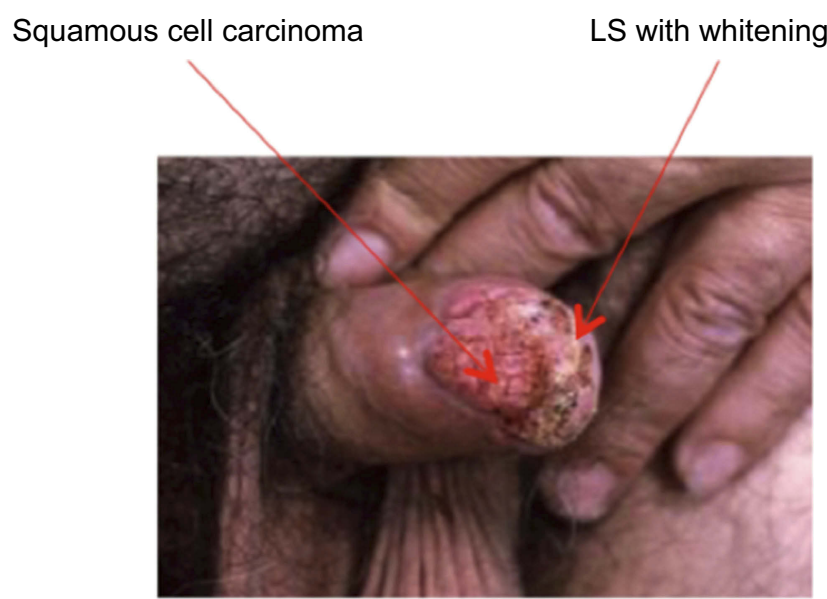

Figure 6 Penile squamous cell carcinoma associated with lichen sclerosus.

The following factors are presumed to have a role in the malignant transformation of LS: chronic inflammation, variation in the gene expression of tumor suppressor p53 (encoded by the TP53 gene) and oxidative DNA damage. ${ }^{26,44-46}$ Various studies have shown a significant overexpression of p53, at times with altered gene expression, in patients with LS; particularly if this has been detected by biopsy in old genital lesions, it can bear witness to a high oxidation state, as well as a high risk of malignant transformation. ${ }^{47,48}$

\section{Role of oxidative stress in the pathogenesis of LS Oxidative stress}

In the cells of our body, there is a physiological balance between production and elimination of free radicals (ROS): this is called redox homeostasis. Redox homeostasis is preserved by an endogenous antioxidant system, but when free radicals are produced in excess and/or the endogenous antioxidant system is insufficient in neutralizing them, the physiological balance is impaired, with consequent development of a state of oxidative stress (OS). ${ }^{49}$

It has by now been recognized that OS, which has an important role in the maintenance and progression of inflammation, is decisive in the pathophysiological mechanisms of several chronic and autoimmune inflammatory diseases. ${ }^{49,50}$

\section{Oxidative stress in LS(see Figure I Figure 7)}

As in many other chronic inflammatory disorders and several autoimmune disorders, OS has been proven to play a role in the pathogenesis of LS. ${ }^{46,51-53}$ Sander et al (2004) found that the following were present in LS lesions: products of lipid peroxidation in high concentration in the keratinocytes of the epidermal basal cell layers; oxidative DNA damage in all LS lesions; oxidative protein damage in the areas of dermal sclerosis; low concentrations of the antioxidant enzyme manganese superoxide dismutase (MnSOD) (which is part of the endogenous antioxidant defense system). ${ }^{46}$ Even Li et al (2014) have demonstrated the presence of OS in patients with LS: they detected significantly high levels of malondialdehyde (a lipid peroxidation marker), associated with low levels of endogenous antioxidant SOD. ${ }^{54}$ The same Authors, along with a state of OS, also found an excessive immunoreaction consisting in lower levels of CD4+ T cells and higher levels of CD8+ T cells, and with a CD4+/CD8+ ratio that is significantly lower in LS patients compared to controls.

As in all conditions of OS, even in LS, there is a damage to the extracellular matrix.$^{55}$ The presence of an oxidative imbalance in the diseased tissues can thus contribute to destroy the tissue of the skin and mucous membranes during LS. $^{54}$

It has been proven, furthermore, that in patients with LS, as in other both cancerous and non-cancerous epithelial diseases, the increase in oxidative DNA damage is associated with downregulation of the expression of p16I ${ }^{\mathrm{INK} 4}$ (a protein encoded by gene CDKN2A/cyclindependent kinase inhibitor $2 \mathrm{~A}$ ) and $\mathrm{p} 27^{\mathrm{Kip} 1}$ (a protein encoded by gene CDKN1B/cyclin-dependent kinase inhibitor $1 \mathrm{~B}) .{ }^{56}$ These two proteins, $\mathrm{p} 16 \mathrm{I}^{\mathrm{INK} 4}$ and $27^{\mathrm{Kip} 1}$, are part of the system of cyclin-dependent kinase inhibitors that is essential for cell cycle control; $\mathrm{p} 16 \mathrm{I}^{\mathrm{INK} 4}$ and $\mathrm{p} 27^{\mathrm{Kip} 1}$ work as negative regulators of the cell cycle (G1 phase) and are considered tumor suppressors.

It has also been shown that the levels of 8-hydroxydeoxy-guanosine (8-OHdG), a biomarker of oxidative DNA damage, increase progressively as one goes from non-cancerous skin lesions, as in LS, to cases of vulvar intraepithelial neoplasia, and finally invasive vulvar carcinomas. $^{56}$

Han et al (2018) sequenced the entire exome (the set of all the portions of the genome that encode for proteins), searching for mutational signatures and chromosome alterations of the profiles of vulvar squamous cell carcinomas (vulvar SCCs), both HPV (+) and HPV (-). Besides the known alterations of TP53, CDKN2A, HRAS in HPVnegative SCCs, the authors of the study found two types of molecular signatures. ${ }^{44,45,47,48,56}$ The first type of mutation is characterized by deamination of 5-methyl-cytosine, which can be found in most human cancers and is probably associated with aging; the second mutational 
signature is characterized by over-activity of the APOBEC enzymes, which results in aberrant DNA methylation. APOBEC is a family of cytidine deaminases whose specific role is involved in DNA replication and DNA repair mechanisms. Since DNA damage from OS is always present in LS, it is very likely that the mutation of the APOBEC enzymes has a specific role in facilitating the subsequent transformation of LS into SCC. ${ }^{44,54,56-58}$

It appears evident, as in other chronic inflammation processes, that OS plays an important role not only in the pathogenesis, but also in the development, maintenance, and progression of LS. Furthermore, OS, by causing DNA damage, contributes directly to malignant transformation of the disease (Figure 7).

\section{Treatment}

There is no single treatment strategy to be recommended for LS; in any case, patients should always be told about the various treatment options and the pros and cons of each.

Treatment is always indicated, particularly because this reduces the possibility that LS lesions may develop into malignant disease. $4,6,7,37,46,59$ The overview of treatment options is ample: high potency topical corticosteroids (Clobetasol propionate, Mometasone), topical Tacrolimus and topical Pimecrolimus (immunosuppressants, calcineurin inhibitors), testosterone treatments, systemic therapies (oral retinoids, oral vitamin $\mathrm{E}$ and other antioxidants, steroid injections, cyclosporine, methotrexate, hydroxyurea, etc.), surgery, cryotherapy, photodynamic therapy, phototherapy, laser, and stem cell transplants with plateletrich plasma. ${ }^{6,59-61}$ Various international guidelines all recommend, especially when the disease is in its early stages, intensive topical treatment with high potency corticosteroids for at least 3 months and, as a second step, when there is no response, treatment with non-steroid topical immunosuppressants. ${ }^{6,59-61}$ No therapeutic effect has been shown for topical testosterone, dihydrotestosterone, or progesterone, while oral and topical use of retinoids has proven its efficacy. ${ }^{59}$ Surgical treatment is indicated in the following cases: in males with severe phimosis secondary to advanced $\mathrm{BXO}$, where circumcision is indicated; in both sexes, in case of stenosis of the

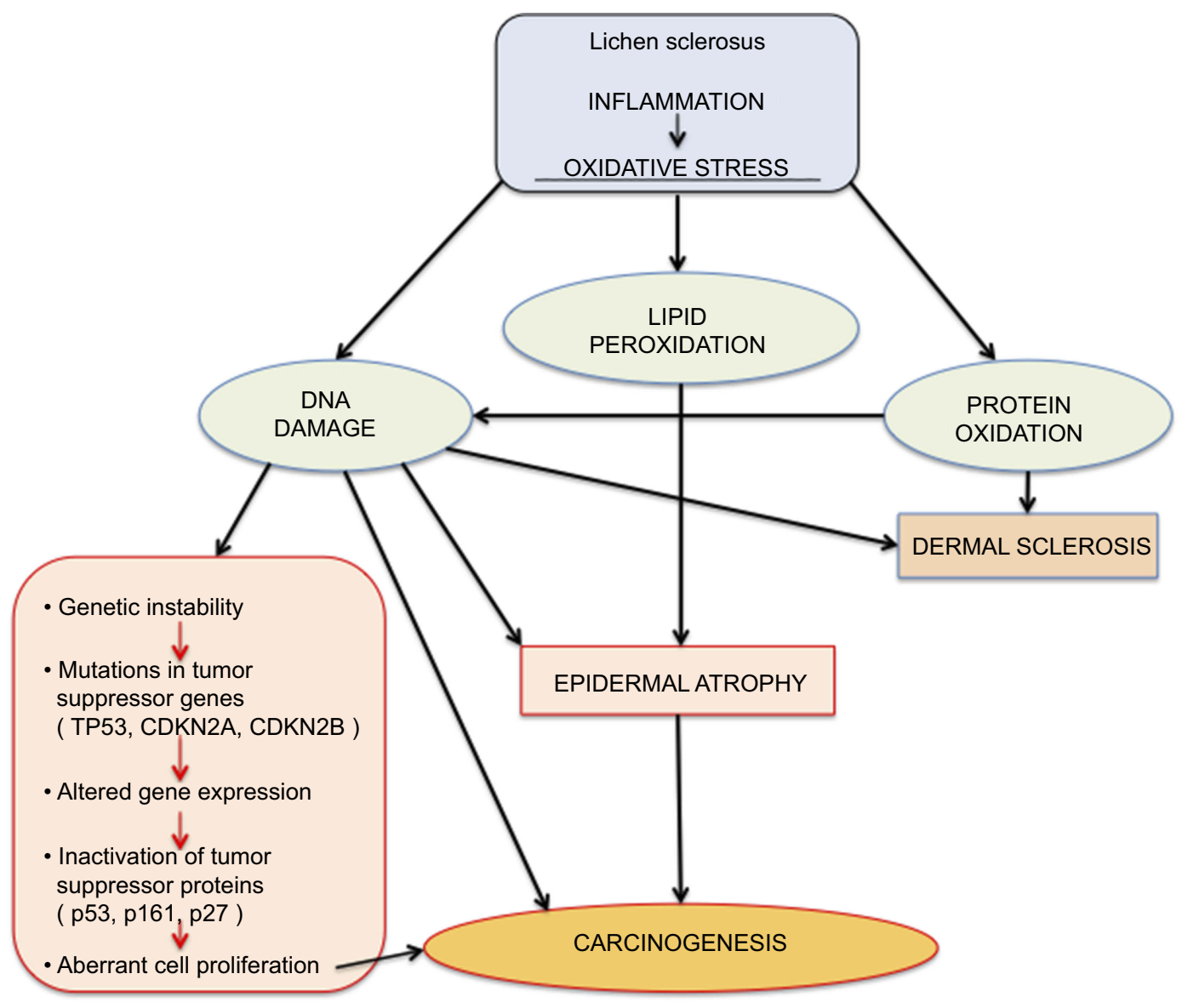

Figure 7 Oxidative stress mechanisms in lichen sclerosus. 
meatus and/or urethra; in females in case of local complications (introital stenosis, labial fusion) plastic surgery is indicated to solve the functional impairment; in not overly severe cases of clitoral phimosis, it is possible to use laser therapy (either as a standalone therapy or in association with plastic surgery in select cases). ${ }^{6,59,61}$

\section{Discussion and conclusions}

In the literature, a number of trials have already shown the presence and role of OS in the pathophysiological mechanisms of LS. ${ }^{44,54,56}$ Lesions typical of LS, such as hyperkeratosis, epidermal atrophy, and dermal sclerosis are associated with a high concentration of products of lipid peroxidation in the keratinocytes of the epidermal basal cell layers. ${ }^{46}$ Moreover, in patients with LS, in the dermal areas of sclerosis and areas where phlogosis is present, there are high concentrations of oxidatively modified proteins; furthermore, the concentrations of 8-OhdG (a biomarker of oxidative DNA damage) are significantly higher in the epidermal keratinocytes, dermal fibroblasts, and the cells within the inflamed area of the dermis. ${ }^{46}$

OS, through lipid peroxidation, is likely the most significant cause of tissue damage and consequent fibrosis, which, as the disease progresses, causes its late complications. ${ }^{46} \mathrm{OS}$ is, therefore, integral part of the disease and has an influence on its progression, including its possible malignant transformation. The crucial points in which OS can decisively contribute to carcinogenesis arising from LS lesions are the following: oxidative DNA damage, lipid peroxidation, and epidermal atrophy. ${ }^{46,47}$

Oxidative DNA damage, by causing a persistent, continuous stimulus to cell and tissue regeneration, heavily contributes to malignant transformation of the disease. ${ }^{46,47,62-64}$ In addition, the powerful mutagenic effect of free radicals produced by activated macrophages present in excessive amounts in the inflammatory infiltrate in LS is well known. ${ }^{44} \mathrm{OS}$, as mentioned above, besides having the potential to cause mutations in genes CDKN2A, CDKN1B, and APOBEC, can also cause genetic mutations of tumor suppressor protein p53 (encoded by the TP53 gene) with secondary production of mutant p53, and in these cases it is very likely that a progression towards malignancy is already taking place. ${ }^{47,48}$ With respect to this, Rolfe et al (2003) found high amounts of TP53 mutations in LS sites adjacent to invasive vulvar SCC. ${ }^{44}$ Vulvar LS, being a chronic fibrotic inflammatory disease with an evident phenotype of keratinocyte proliferation, has therefore been considered a starter condition favoring the development of SCC, since-due to the strong oxidation state-DNA damage is constantly present. $^{47,64}$
Proof of how important oxidative DNA damage is as a condition favoring disease progression and transformation into carcinoma lies in the fact that the tissue concentrations of the specific biomarker of oxidate DNA damage have been shown to increase from one pathological condition to the other, in the following order: LS; non-invasive vulvar carcinoma; invasive vulvar carcinoma. ${ }^{56}$

Consequently, it is necessary to begin LS treatment as soon as the disease is recognized, and, if necessary, when there is any doubt about the diagnosis, after carrying out histological assessment.

Considering the role that OS plays in LS, therapeutic use of antioxidants, therefore, appears to be rational and possible, in association with other types of treatment. The purpose of this treatment option is not only that of reducing the damaging effects of OS on cells and tissues, but also of hindering the progression of LS and reducing the risk of malignant transformation.

In this regard, several studies in the literature have shown the efficacy of the use of antioxidants in preventing carcinoma development. ${ }^{65-74}$

On the other hand, articles reporting studies using antioxidants as treatment in patients with LS are very few in the literature. ${ }^{75-77}$ In these studies, positive therapeutic effects were achieved using various antioxidant substances: olive oil-based polyphenol-rich cream and vitamin E; Avocado and soybean extracts in cream and capsule form; Vitamin E ointment.

Further, randomized controlled studies are therefore needed to evaluate and confirm the efficacy of treatments with antioxidants, since these substances could not only support other treatments, strengthening their therapeutic effects, but, what is more, they would counteract the oxidative DNA damage, which is the most important factor for the progression of LS and its malignant transformation.

\section{Disclosure}

The authors report no conflicts of interest in this work.

\section{References}

1. Ganesan L, Parmar H, Das JK, Gangopadhyay A. Extragenital lichen sclerosus et atrophicus. Indian $J$ Dermatol. 2015;60(4):420. doi:10.4103/0019-5154.160516

2. Ballester I, Bañuls J, Pérez-Crespo M, Lucas A. Extragenital bullous lichen sclerosus atrophicus. Dermatol Online J. 2009;15(1):6.

3. Wallace HJ. Lichen sclerosus et atrophicus. Trans St Johns Hosp Dermatol Soc. 1971;57(1):9-30.

4. Powell JJ, Wojnarowska F. Lichen sclerosus. Lancet. 1999;22:17771783. 
5. Pugliese JM, Morey AF, Peterson AC. Lichen sclerosus: review of the literature and current recommendations for management. $J$ Urol. 2007;178(6):2268-2276. doi:10.1016/j.juro.2007.08.024

6. Lewis FM, Tatnall FM, Velangi SS, et al. British Association of Dermatologists guidelines for the management of lichen sclerosus, 2018. Br J Dermatol. 2018;178(4):839-853. doi:10.1111/bjd.16241

7. Fistarol SK, Itin PH. Diagnosis and treatment of lichen sclerosus: an update. Am J Clin Dermatol. 2013;14(1):27-47. doi:10.1007/s40257012-0006-4

8. Leibovitz A, Kaplun VV, Saposhnicov N, Habot B. Vulvovaginal examinations in elderly nursing home women residents. Arch Gerontol Geriatr. 2000;31(1):1-4.

9. Kizer WS, Prarie T, Morey AF. Balanitis xerotica obliterans: epidemiologic distribution in an equal access health care system. South Med J. 2003;96(1):9-11. doi:10.1097/00007611-200301000-00004

10. Tokgöz H, Polat F, Tan MO, Erdem O, Bozkirli I. Histopathological evaluation of the preputium in preschool and primary school boys. Int Urol Nephrol. 2004;36(4):573-576. doi:10.1007/s11255-004-0857-6

11. Irkilata L, Bakirtas M, Aydin HR, et al. Pathological investigation of childhood Foreskin: are lichen sclerosus and phimosis common? J Coll Physicians Surg Pak. 2016;26(2):134-137. doi:02.2016/JCPSP.134137

12. Harrington CI, Dunsmore IR. An investigation into the incidence of auto-immune disorders in patients with lichen sclerosus and atrophicus. $B r ~ J$ Dermatol. 1981;104(5):563-566. doi:10.1111/j.13652133.1981.tb08172.x

13. Meyrick Thomas RH, Ridley CM, Black MM. The association of lichen sclerosus et atrophicus and autoimmune-related disease in males. Br J Dermatol. 1983;109(6):661-664. doi:10.1111/j.13652133.1983.tb00546.x

14. Guarneri F, Giuffrida R, Di Bari F, Cannavò SP, Benvenga S. Thyroid autoimmunity and lichen. Front Endocrinol (Lausanne). 2017;8:146.

15. Chan I, Oyama N, Neill SM, Wojnarowska F, Black MM, McGrath JA. Characterization of $\mathrm{IgG}$ autoantibodies to extracellular matrix protein 1 in lichen sclerosus. Clin Exp Dermatol. 2004;29(5):499504. doi:10.1111/j.1365-2230.2004.01573.x

16. Edmonds EV, Oyama N, Chan I, Francis N, McGrath JA, Bunker CB. Extracellular matrix protein 1 autoantibodies in male genital lichen sclerosus. Br J Dermatol. 2011;165(1):218-219. doi:10.1111/j.13652133.2011.10326.x

17. Kantere D, Alvergren G, Gillstedt M, Pujol-Calderon F, Tunbäck P. Clinical features, complications and autoimmunity in male lichen sclerosus. Acta Derm Venereol. 2017;97(3):365-369. doi:10.2340/00015555-2537

18. Edmonds EV, Hunt S, Hawkins D, Dinneen M, Francis N, Bunker CB. Clinical parameters in male genital lichen sclerosus: a case series of 329 patients. J Eur Acad Dermatol Venereol. 2012;26(6):730-737. doi:10.1111/j.1468-3083.2011.04155.x

19. Kreuter A, Kryvosheyeva Y, Terras S, et al. Association of autoimmune diseases with lichen sclerosus in 532 male and female patients. Acta Derm Venereol. 2013;93(2):238-241. doi:10.2340/00015555-1512

20. Marren P, Yell J, Charnock FM, Bunce M, Welsh K, Wojnarowska F. The association between lichen sclerosus and antigens of the HLA system. Br J Dermatol. 1995;132(2):197-203. doi:10.1111/j.13652133.1995.tb05013.x

21. Azurdia RM, Luzzi GA, Byren I, et al. Lichen sclerosus in adult men: a study of HLA associations and susceptibility to autoimmune disease. $B r \quad J$ Dermatol. 1999;140(1):79-83. doi:10.1046/j.13652133.1999.02611.x

22. Powell J, Wojnarowska F, Winsey S, Marren P, Welsh K. Lichen sclerosus premenarche: autoimmunity and immunogenetics. $\mathrm{Br} J$ Dermatol. 2000;142(3):481-484. doi:10.1046/j.1365-2133.2000.03360.x

23. Kirtschig G, Kuik DJ. A dutch cohort study confirms familial occurrence of anogenital lichen sclerosus. $J$ Women's Health Care. 2014;3:209-211.
24. Sherman V, McPherson T, Baldo M, Salim A, Gao XH, Wojnarowska F. The high rate of familial lichen sclerosus suggests a genetic contribution: an observational cohort study. J Eur Acad Dermatol Venereol. 2010;24(9):1031-1034. doi:10.1111/j.1468-3083.2010.03572.x

25. Al-Niaimi F, Lyon C. Peristomal lichen sclerosus: the role of occlusion and urine exposure? Br J Dermatol. 2013;168(3):643-646. doi:10.1111/bjd.12014

26. Miller RA. The Koebner phenomenon. Int J Dermatol. 1982;21 (4):192-197.

27. Eisendle K, Grabner T, Kutzner H, Zelger B. Possible role of Borrelia burgdorferi sensu lato infection in lichen sclerosus. Arch Dermatol. 2008;144(5):591-598. doi:10.1001/archderm.144.5.591

28. Edmonds E, Mavin S, Francis N, Ho-Yen D, Bunker C. Borrelia burgdorferi is not associated with genital lichen sclerosus in men. $\mathrm{Br} \mathrm{J}$ Dermatol. 2009;160(2):459-460. doi:10.1111/j.1365-2133.2008.08969.x

29. Kirtschig G. Lichen sclerosus-presentation, diagnosis and management. Dtsch Arztebl Int. 2016;113(19):337-343. doi:10.3238/ arztebl.2016.0337

30. Shasi PB, Chapman HT, Evans DT, Jaleel H. Psychological and psychiatric morbidity in lichen sclerosus in a cohort recruited from a genitourinary medicine clinic. Int J STD AIDS. 2010;21(1):17-18. doi:10.1258/ijsa.2009.009102

31. van Cranenburgh OD, Nijland SB, Lindeboom R, et al. Patients with lichen sclerosus experience moderate satisfaction with treatment and impairment of quality of life: results of a cross-sectional study. $\mathrm{Br} J$ Dermatol. 2017;176(6):1508-1515. doi:10.1111/bjd.15125

32. Van de Nieuwenhof HP, Meeuwis KA, Nieboer TE, Vergeer MC, Massuger LF, De Hullu JA. The effect of vulvar lichen sclerosus on quality of life and sexual functioning. J Psychosom Obstet Gynaecol. 2010;31(4):279-284. doi:10.3109/0167482X.2010.507890

33. Depasquale I, Park AJ, Bracka A. The treatment of balanitis xerotica obliterans. BJU Int. 2000;86(4):459-465.

34. Niamh L, Naveen S, Hazel B. Diagnosis of vulval inflammatory dermatoses: a pathological study with clinical correlation. Int J Gynecol Pathol. 2009;28(6):554-558. doi:10.1097/PGP.0b013e3181a9fb0d

35. Liang SX, Zheng W. Vulva and vagina, lichen sclerosus. In: Essential of Anatomic Pathology. Vol. 2, 4th ed. Cheng L, Bostwick DG, editors. Basel, Switzerland: Springer International Publishing; 2016: 1462; ISBN 978-3-319-23379-6.

36. Sergeant A, Vernall N, Mackintosh LJ, McHenry P, Leman JA. Squamous cell carcinoma arising in extragenital lichen sclerosus. Clin Exp Dermatol. 2009;34(7):e278-e279. doi:10.1111/j.13652230.2008.03195.x

37. Lee A, Bradford J, Fischer G. Long-term management of adult vulvar lichen sclerosus: a prospective cohort study of 507 women. JAMA Dermatol. 2015;151(10):1061-1067. doi:10.1001/ jamadermatol.2015.0643

38. Leibowitch M, Neill S, Pelisse M, Moyal-Baracco M. The epithelial changes associated with squamous cell carcinoma of the vulva: a review of the clinical, histological and viral findings in 78 women. $\mathrm{Br}$ J Obstet Gynaecol. 1990;97(12):1135-1139.

39. Walkden V, Chia Y, Wojnarowska F. The association of squamous cell carcinoma of the vulva and lichen sclerosus: implications for management and follow up. J Obstet Gynaecol. 1997;17(6):551-553. doi:10.1080/01443619768588

40. Vilmer C, Cavelier-Balloy B, Nogues C, Trassard M, Le Doussal V. Analysis of alterations adjacent to invasive vulvar carcinoma and their relationship with the associated carcinoma: a study of 67 cases. Eur J Gynaecol Oncol. 1998;19(1):25-31.

41. Powell J, Robson A, Cranston D, Wojnarowska F, Turner R. High incidence of lichen sclerosus in patients with squamous cell carcinoma of the penis. Br J Dermatol. 2001;145(1):85-89. doi:10.1046/ j.1365-2133.2001.04287.x 
42. Nasca MR, Innocenzi D, Micali G. Penile cancer among patients with genital lichen sclerosus. J Am Acad Dermatol. 1999;41(6):911-914. doi:10.1016/S0190-9622(99)70245-8

43. Barbagli G, Palminteri E, Mirri F, Guazzoni G, Turini D, Lazzeri M. Penile carcinoma in patients with genital lichen sclerosus: a multicenter survey. J Urol. 2006;175(4):1359-1363. doi:10.1016/S00225347(05)00735-4

44. Rolfe KJ, MacLean AB, Crow JC, Benjamin E, Reid WM, Perrett CW. TP53 mutations in vulval lichen sclerosus adjacent to squamous cell carcinoma of the vulva. Br J Cancer. 2003;89(12):2249-2253. doi:10.1038/sj.bjc. 6601444

45. Hantschmann P, Sterzer S, Jeschke U, Friese K. P53 expression in vulvar carcinoma, vulvar intraepithelial neoplasia, squamous cell hyperplasia and lichen sclerosus. Anticancer Res. 2005;25 (3A):1739-1745.

46. Sander CS, Ali I, Dean D, Thiele JJ, Wojnarowska F. Oxidative stress is implicated in the pathogenesis of lichen sclerosus. Br J Dermatol. 2004;151(3):627-635. doi:10.1111/j.1365-2133.2004.06142.x

47. Tapp RA, Feng J, Jones JW, Carlson JA, Wilson VL. Single base instability is promoted in vulvar lichen sclerosus. J Invest Dermatol. 2007;127(11):2563-2576. doi:10.1038/sj.jid.5700889

48. Gambichler T, Kammann S, Tigges C, et al. Cell cycle regulation and proliferation in lichen sclerosus. Regul Pept. 2011;167(2-3):209-214. doi:10.1016/j.regpep.2011.02.003

49. Lugrin J, Rosenblatt-Velin N, Parapanov R, Liaudet L. The role of oxidative stress during inflammatory processes. Biol Chem. 2014;395 (2):203-230. doi:10.1515/hsz-2013-0241

50. Mittal M, Siddiqui MR, Tran K, Reddy SP, Malik AB. Reactive oxygen species in inflammation and tissue injury. Antioxid Redox Signal. 2014;20(7):1126-1167. doi:10.1089/ars.2012.5149

51. Smallwood MJ, Nissim A, Knight AR, Whiteman M, Haigh R, Winyard PG. Oxidative stress in autoimmune rheumatic diseases. Free Radic Biol Med. 2018;125:3-14. doi:10.1016/j. freeradbiomed.2018.05.086

52. Vona R, Giovannetti A, Gambardella L, Malorni W, Pietraforte D, Straface E. Oxidative stress in the pathogenesis of systemic scleroderma: an overview. J Cell Mol Med. 2018;22(7):3308-3314. doi: $10.1111 /$ jcmm. 13630

53. Paulis G, Romano G, Paulis L, Barletta D. Recent pathophysiological aspects of peyronie's disease: role of free radicals, rationale, and therapeutic implications for antioxidant treatment-literature review. Adv Urol. 2017;2017:4653512. Available from: https://www.ncbi. nlm.nih.gov/pmc/articles/PMC5514334/pdf/AU2017-4653512.pdf. Accessed February 12, 2019.

54. Li GT, Guo SZ, Liu YJ, Yang B. Alteration of T-cell subpopulations and lipid peroxidation in the blood of patients with vulvar nonneoplastic epithelial disorder. Clin Exp Obstet Gynecol. 2014;41 (2):174-176.

55. Kennett EC, Chuang CY, Degendorfer G, Whitelock JM, Davies MJ. Mechanisms and consequences of oxidative damage to extracellular matrix. Biochem Soc Trans. 2011;39(5):1279-1287. doi:10.1042/ BST0391279

56. Zannoni GF, Faraglia B, Tarquini E, et al. Expression of the CDK inhibitor p27kip1 and oxidative DNA damage in non-neoplastic and neoplastic vulvar epithelial lesions. Mod Pathol. 2006;19(4):504513. doi:10.1038/modpathol.3800532

57. Han MR, Shin S, Park HC, et al. Mutational signatures and chromosome alteration profiles of squamous cell carcinomas of the vulva. Exp Mol Med. 2018;50(2):e442. doi:10.1038/emm.2017.265

58. Rebhandl S, Huemer M, Greil R, Geisberger R. AID/APOBEC deaminases and cancer. Oncoscience. 2015;2(4):320-333. doi:10.18632/oncoscience. 155

59. Kirtschig G, Becker K, Günthert A, et al. Evidence-based (S3) Guideline on (anogenital) Lichen sclerosus. J Eur Acad Dermatol Venereol. 2015;29(10):e1-e43. doi:10.1111/jdv.13136
60. Franic D, Iternička Z, Franić-Ivanišević M. Platelet-rich plasma (PRP) for the treatment of vulvar lichen sclerosus in a premenopausal woman: a case report. Case Rep Womens Health. 2018;18:e0062. doi:10.1016/j.crwh.2018.e00062

61. Hasegawa M, Ishikawa O, Asano Y, et al. Diagnostic criteria, severity classification and guidelines of lichen sclerosus et atrophicus. $J$ Dermatol. 2018;45(8):891-897. doi:10.1111/1346-8138.14171

62. Seril DN, Liao J, Yang GY, Yang CS. Oxidative stress and ulcerative colitis-associated carcinogenesis: studies in humans and animal models. Carcinogenesis. 2003;24(3):353-362. doi:10.1093/carcin/24.3.353

63. Shacter E, Weitzman SA. Chronic inflammation and cancer. Oncology (Williston Park). 2002;16(2):217-229. Available from: https://www.cancernetwork.com/colorectal-cancer/chronic-inflamma tion-and-cancer. Accessed February 12, 2019.

64. Carlson JA, Ambros R, Malfetano J, et al. Vulvar lichen sclerosus and squamous cell carcinoma: a cohort, case control, and investigational study with historical perspective; implications for chronic inflammation and sclerosis in the development of neoplasia. Hum Pathol. 1998;29(9):932-948.

65. Chen JX, Li G, Wang H, et al. Dietary tocopherols inhibit PhIPinduced prostate carcinogenesis in CYP1A-humanized mice. Cancer Lett. 2016;371(1):71-78. doi:10.1016/j.canlet.2015.11.010

66. Ding H, Han C, Guo D, et al. Selective induction of apoptosis of human oral cancer cell lines by avocado extracts via a ROS-mediated mechanism. Nutr Cancer. 2009;61(3):348-356. doi:10.1080/ 01635580802567158

67. Parada B, Reis F, Cerejo R, et al. Omega-3 fatty acids inhibit tumor growth in a rat model of bladder cancer. Biomed Res Int. 2013;2013:368178. doi:10.1155/2013/368178

68. Kumar V, Bhatt PC, Rahman M, Al-Abbasi FA, Anwar F, Verma A. Umbelliferon- $\alpha$-d-glucopyranosyl-(2I $\rightarrow 1 \mathrm{II})-\alpha$-Dglucopyranoside ameliorates Diethylnitrosamine induced precancerous lesion development in liver via regulation of inflammation, hyperproliferation and antioxidant at pre-clinical stage. Biomed Pharmacother. 2017;94:834-842. doi:10.1016/j.biopha.2017.07.047

69. Katiyar SK. Dietary proanthocyanidins inhibit UV radiation-induced skin tumor development through functional activation of the immune system. Mol Nutr Food Res. 2016;60(6):1374-1382. doi:10.1002/ mnfr.201501026

70. Sahin K, Cross B, Sahin N, et al. Lycopene in the prevention of renal cell cancer in the TSC2 mutant Eker rat model. Arch Biochem Biophys. 2015;572:36-39. doi:10.1016/j.abb.2015.01.006

71. Lin Y, Yngve A, Lagergren J, Lu Y. A dietary pattern rich in lignans, quercetin and resveratrol decreases the risk of oesophageal cancer. $\mathrm{Br}$ J Nutr. 2014;112(12):2002-2009. doi:10.1017/S0007114514003055

72. Iqbal M, Okazaki Y, Okada S. Curcumin attenuates oxidative damage in animals treated with a renal carcinogen, ferric nitrilotriacetate (FeNTA): implications for cancer prevention. Mol Cell Biochem. 2009;324(1-2):157-164. doi:10.1007/s11010-008-9994-Z

73. Aoki H, Takada Y, Kondo S, Sawaya R, Aggarwal B, Kondo Y. Evidence that curcumin suppresses the growth of malignant gliomas in vitro and in vivo through induction of autophagy: role of Akt and ERK signaling pathways. Mol Pharmacol. 2007;72:29-39. doi:10.1124/mol.106.033167

74. Aggarwal BB, Banerjee S, Bharadwaj U, Sung B, Shishodia S, Sethi G. Curcumin induces the degradation of cyclin E expression through ubiquitin-dependent pathway and up-regulates cyclin-dependent kinase inhibitors p21 and p27 in multiple human tumor cell lines. Biochem Pharmacol. 2007;73:1024-1032. doi:10.1016/j.bcp.2006.12.010

75. Currò M, Russo T, Ferlazzo N, et al. Anti-inflammatory and tissue regenerative effects of topical treatment with ozonated olive oil/ vitamin $\mathrm{E}$ acetate in balanitis xerotica obliterans. Molecules. 2018;23(3):645. Available from: https://www.ncbi.nlm.nih.gov/pmc/ articles/PMC6017296/pdf/molecules-23-00645.pdf. Accessed February 12, 2019. 
76. Borghi A, Corazza M, Minghetti S, Toni G, Virgili A. Avocado and soybean extracts as active principles in the treatment of mild-to-moderate vulvar lichen sclerosus: results of efficacy and tolerability. J Eur Acad Dermatol Venereol. 2015;29(6):1225-1230. doi:10.1111/jdv.12617
77. Virgili A, Minghetti S, Borghi A, Corazza M. Long-term maintenance therapy for vulvar lichen sclerosus: the results of a randomized study comparing topical vitamin E with an emollient. Eur J Dermatol. 2013;23(2):189-194. doi:10.1684/ejd.2013.1987

\section{Publish your work in this journal}

Research and Reports in Urology is an international, peer-reviewed, open access journal publishing original research, reports, editorials, reviews and commentaries on all aspects of adult and pediatric urology in the clinic and laboratory including the following topics: Pathology, pathophysiology of urological disease; Investigation and treatment of urological disease; Pharmacology of drugs used for the treatment of urological disease. The manuscript management system is completely online and includes a very quick and fair peer-review system, which is all easy to use. Visit http://www.dovepress.com/ testimonials.php to read real quotes from published authors. 